\title{
Oral Cavity Cancers -Level v Metastasis
}

\author{
Amitabh Jena $\cdot$ Raja sundaram $\cdot$ B Manilal • \\ Rashmi Patnayak
}

Received: 22 March 2014 / Accepted: 20 May 2014 / Published online: 3 June 2014

(C) Indian Association of Surgical Oncology 2014

Sir,

We read with interest the article" Significance of level $\mathrm{v}$ lymph node dissection in clinically node positive oral cavity squamous cell carcinoma and evaluation of potential risk factors for level v lymph node metastasis. " by Parikh etal. [1] In this context, we would like to share our experience regarding the lymph node positivity in patients with oral cavity cancers. We had analyzed our data from a tertiary care center in south India where our patients had undergone neck dissection along with surgical ablation of the tumor. [2]

According to our data, of 218 operated cases, 68 were $\mathrm{cN} 0$. Of them 7 cases showed metastasis histopathologically. Out of 150 clinically positive nodes, histopathologically 59 were positive. [2]

In two of our cases, level V lymph nodes were positive. In one case, the primary was retromolar trigone and in the other case it was gingivo-buccal sulcus. Histopathologically, lymphovascular invasion was present in both the cases. [2] Also both these cases showed lymph nodal involvement in other levels.
In our study of female predominant patients, these two patients had undergone reconstruction with pectoralis major myocutaneous flap along with neck dissection (modified radical neck dissection type -2). [3]

We agree with the authors that level V lymph node dissection should be a part of surgery for proper staging and postoperative subsequent treatment and follow-up.

\section{References}

1. Parikh DG, Chheda YP, Shah SV, Patel AM, Sharma MR (2013) Significance of level v lymph node dissection in clinically node positive oral cavity squamous cell carcinoma and evaluation of potential risk factors for level v lymph node metastasis. Indian J Surg Oncol 4:275-9

2. Jena A, Patnayak R, Vamsi RN, Reddy SK, Banoth M (2013) Surgical management of the neck in oral cancers: A single-institute experience from South India. Arch Int Surge 3:106-11

3. Jena A, Patnayak R, Sharan R, Reddy SK, Manilal B, Rao LM (2014) Outcomes of pectoralis major myocutaneous flap in female patients for oral cavity defect reconstruction. J Oral Maxillofac Surg 72:222-31

\footnotetext{
A. Jena $\cdot$ R. sundaram $\cdot$ B. Manilal

Department of Surgical Oncology, Sri Venkateswara Institute Of

Medical Sciences, Tirupati, Andhra Pradesh -517507, India

A. Jena

e-mail: dramitabh2004@yahoo.com

R. Patnayak $(\bowtie)$

Department of Pathology, Sri Venkateswara Institute Of Medical

Sciences, Tirupati, Andhra Pradesh -517507, India

e-mail: rashmipatnayak2002@yahoo.co.in
} 